\title{
Influence of Subgrade Stiffness on Flexible Pavement Responses - A Case Study-Alexandria City, Egypt
}

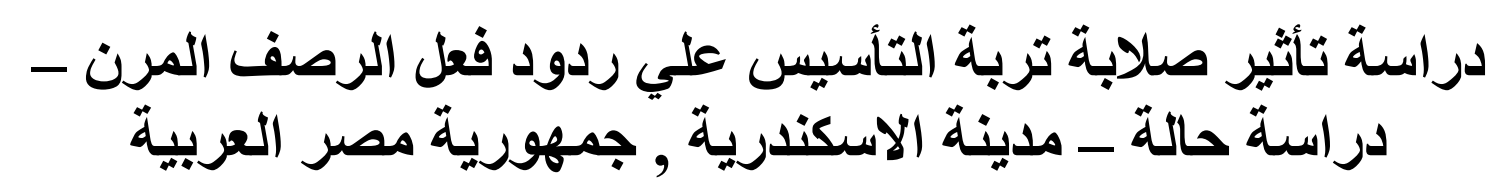

Saad El-Hamrawy*, R. Abd El-Hakim**

Prof. of Highway Eng., Pharos University, Alexandria, Egypt

**Assistant professor, Public Works Engineering Department, Faculty of

Engineering, Tanta University, E-mail: ragaa.abdelhakim@f-eng.tanta.edu.eg

تقع مدينة الاسكندرية في شمال جمهورية مصر العربية علي البحر المتوسط وتتنوع الطبقات العليا من التربة في

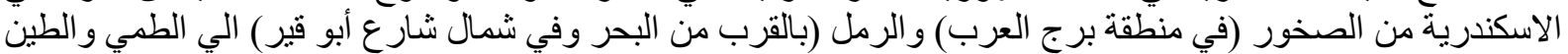

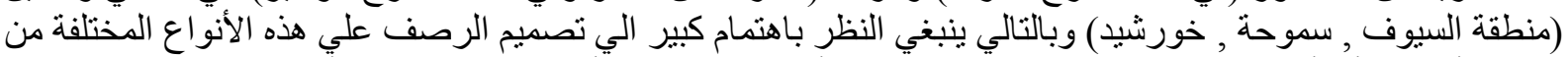

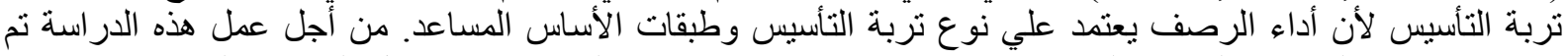

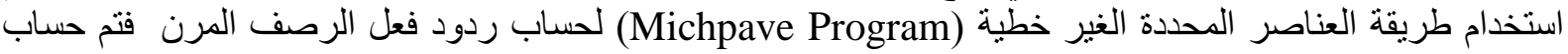

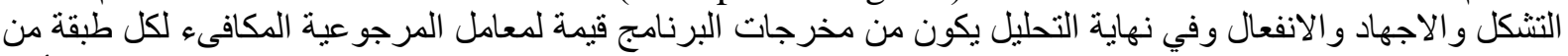

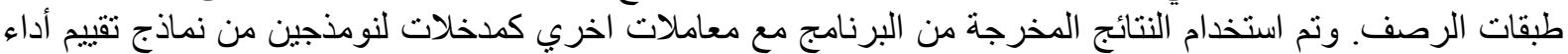
الرصف للتنبؤ بعمر الرصف و ومثق التخدد. وقد كانت هذه النماذج مقتصرة علي ثنلاث طبقات هي طبقة الخرسانة الاسفلتية و الأساس وطبقة التأسيس فتم تحليلها باستخدام 4 طبقات هي الخرسانة الأسفلتية و الأساس و الأساس المساعد فون فوق

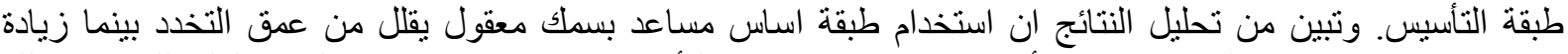

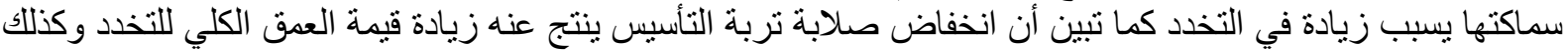
عمق التخدد الناتج في طبقة الرصف الاسفلتي في حين أن قيمة عمر الرصف نزيد مع زيادة صدابة نربة التأسيس.

\section{Abstract:}

Alexandria city lies at the north of Egypt on the Mediterranean Sea. The top layers of soil in Alexandria differs from bed rock (Borg El-Arab), sand (near the sea, north Abo-Qir street) to silt and clay (Elsyouf, Smouha, Khorshed, etc..). Thus, a great attention should be considered in the design of pavements on these dissimilar subgrades because the performance of a pavement depends on the quality of its subgrade and subbase layers.

The non-linear finite element program MICHPAVE is used in this study to analyze the flexible pavement responses. Displacements, stresses and strains are computed only within the region modeled by finite elements. At the end of the analysis, MICHPAVE outputs an equivalent resilient modulus for each pavement layer. Results from the non-linear mechanistic analysis, together with other parameters, are used as input to two performance models, to predict the fatigue life and rut depth. These performance models are currently restricted to three-layer pavements with asphalt concrete (AC) surface, base and roadbed soil, and four-layer pavements with AC surface, base, subbase and roadbed soil.

Analysis of research results has shown that using a reasonable subbase layer reduces the rut depth of pavement while the increase in subbase thickness causes increase in rutting. Total expected rut depth of pavement as well as expected rut depth in the asphalt course increase with the decrease of subgrade stiffness, while fatigue life of pavement increases with the increase of subgrade stiffness.

\section{Key Words}

Subgrade, Rutting depth, Axle loads, Fatigue damage, Finite Element, MICHPAVE 


\section{Introduction and Background}

Subgrade is the foundation layer for supporting highways. Stiffness of this layer is a crucial parameter as it upholds the traffic loadings. Studies conducted on pavements structural design indicated that the input value of stiffness modulus has a great influence on the determined thickness for the subbase, base course, and asphalt layer. Numerous studies have indicated that many cases of fatigue or rutting failures refer to inadequate stiffness of soil subgrade layers $[1,2,3,4,5,6]$.

\subsection{Subgrade Soils}

With varying traffic and environmental conditions in a pavement structure, the most significant influence on pavement design and thickness determination is often by subgrade soils. This influence is the most pronounced at low subgrade support values, i.e., for weal soils. Factors that have a significant effect on the soil behavior can be loading condition, stress state, soil type, compaction, and soil physical states. The most important stress factor for soils is the deviator stress. Although the resilient modulus typically increases with increasing confining stress, the deviator stress has the most significant effect on resilient modulus of fine-grained subgrade soils. Therefore, constitutive relationships are primarily established between the resilient behavior and the deviator stress. In addition, the physical state is mainly represented by moisture content and dry density for compaction characteristics, Liquid Limit (LL), Plastic Limit (PL), Plasticity Index (PI), and saturation levels. Soil suction is controlled by grain size distribution, internal soil structure, and the closeness of the ground water table and has a major influence on subgrade moisture content.

\subsection{Importance of Stiffness Modulus of Subgrade:}

Determination of pavement layer thickness is governed by the stiffness of subgrade and granular layers, thus information on the stiffness modulus of subgrade and granular layers is required before pavement design. If the stiffness value of base, subbase and subgrade layers is high, it means that these layers have higher stress distribution ability and consequently, the required thickness of pavement can be reduced using the stiffer layers.

Barksdale and Itani [1] indicated that uncrushed gravels have a lower stiffness modulus than crushed stones making them more susceptible to rutting. Zakaria and leest [2] reported that pavement strain is strongly dependent on aggregate type, fines content, moisture content, compaction and load applications.

Giroud and Han [3] stated that, bearing capacity failure of the base course or subgrade after repeated loads is the main cause of surface rutting. $\mathrm{Xu}$ and Huang [4] concluded that most rutting is related to the weakness in the middle and lower layers.

In terms of fatigue failure, Mulungye et al. [5] stated that even in weak subgrade, fatigue cracking occurred before rutting. Cardone et al.[6] concluded that the stiffness of the soil and granular layer must be sufficiently high to avoid fatigue cracking.

\subsection{Effect of Axle loads and Tire pressure}

Trucks are a major consumer of the pavement structure because they apply the heavy loads to the road surface and consequently are considered one of the main inputs of pavement design procedure. One principle of pavement design specifies that different axle loads, tire pressures and 
load configuration produce different stresses and strains in the various layers of a pavement structure [7].

One of the major trends, which assure saving in Vehicle Operating Cost is increasing truck-axle loads and truck-tire pressures [8]. So, over the past few years, many countries have increased the legal limits of truck-axle loads [9]. The legal truck-axle loads in Egypt were increased to 13-ton (28-kip) and 20-ton (44-kip), for single axle dual wheel and dual tandem axle, respectively [10].

\section{Finite Element Programs For Pavement Analysis}

Finite element models have been applied extensively to analysis of pavement structures. In this section, the development of several nonlinear solution techniques including finite element methods currently used in pavement analysis are reviewed.

\subsection{Two-Dimensional or Axisymmetric Finite Element Analysis}

ILLI-PAVE is a commonly used finite element program developed at the University of Illinois [11] and the MICHPAVE program was developed at the Michigan State University [12] for the analysis of flexible pavements. Both programs modeled the pavement as an axisymmetric solid of revolution and used the following resilient response models, the $\mathrm{K}-\theta$ model for granular materials, and the bilinear approximation for fine-grained subgrade soils. The principal stresses in the granular and subgrade layers did not exceed the strength of material as defined by the Mohr-Coulomb theory of failure. MICH-PAVE used a flexible boundary at a limited depth beneath the surface of the subgrade, instead of a rigid boundary placed deeper in the subgrade and then reduced run time and storage requirements. In addition, the analyses of MICH-PAVE yielded outcomes with a reduced run time and storage requirements compared to other programs.

Brunton and De Almeida [13] developed a finite element program named FENLAP for structural analysis of pavements. The program incorporated various nonlinear stress-strain models, such as the Brown and Loach's model for subgrades and the popular $\mathrm{K}-\theta$ model for granular materials to simulate the resilient behavior. An incremental and iterative procedure very similar to the one used in SENOL program is employed for nonlinear analysis. Modulus values are obtained for the elastic stiffness which calculated the average resilient modulus in the linear elastic layers to be used with falling weight deflectometer back calculation procedures. Although the $\mathrm{K}-\theta$ model was not appropriate for characterization of the granular layers, the model gave reasonable results in terms of vertical displacements of pavements.

A nonlinear finite element program that combines the nonlinear stressdependent modulus for unbound granular base layer and Poisson's ratio for all layers was developed

By Park et al. [14]. The developed program was verified by comparing the results to those obtained from the BISAR program. They modeled the stressdependency for granular materials suitable for calculating a reduced horizontal tension in the bottom half of the unbound base layers. Unlike conventional methods for correcting horizontal tension, compressive stresses could be obtained only by the use of constitutive models.

\subsection{Finite Element Program MICHPAVE \\ MICHPAVE is a user-friendly, non-} linear finite element program for the analysis of flexible pavements. The program computes displacements, stresses and strains within the pavement due to a single circular wheel load. Useful design information such as fatigue life and rut 
depth is also estimated through empirical equations.

\subsubsection{Modeling of the Pavement}

Each layer in a pavement cross section is assumed to extend infinitely in the horizontal directions, and the last layer is assumed to be infinitely deep. All the pavement layers are assumed to be fully bonded so that no slip occurs due to applied load. Displacements, stresses and strains due to a single circular wheel load are computed. Due to the assumptions used, the problem is reduced to an axisymmetric one.

\subsubsection{Granular and Cohesive Material Models}

The so-called $K-\Theta$ model is used to characterize the resilient moduli of granular (type 2) materials [15]. This model is of the form

$$
M_{R}=K_{1} \Theta^{K}
$$

In which $\theta=\sigma_{1}+\sigma_{2}+\sigma_{3}=$ bulk stress and $M_{R}=$ resilient modulus, and $K_{1}$ and $K_{2}$ are material properties. The resilient modulus for cohesive soils is specified in terms of the deviator stress through the bilinear model:

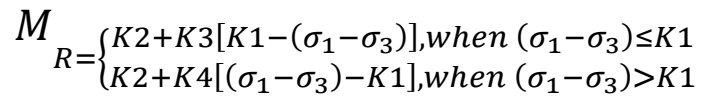

\subsubsection{Gravity and Lateral Stresses}

The MICHPAVE program includes the effect of gravity and lateral stresses arising from the weight of the materials. At any location within the pavements, the vertical gravity stress $(\sigma g)$ is computed as the accumulation of the layer thicknesses multiplied by the appropriate unit weights. The lateral stress is taken as

$$
\sigma_{h}=K_{0} \sigma_{g}
$$

Where: $K_{0}=$ coefficient of earth pressure at rest. For granular soils $K_{0}=1-$ $\sin \phi$ and for cohesive soils $K_{0}=1-0.95 \sin$ $\phi$, where $\phi=$ angle of internal friction.
To approximately account for "locked-in" stresses caused by compaction, the user can input a value for $K_{0}$ higher than the coefficient of earth pressure at rest.

\section{Finite Element Analysis}

\subsection{Investigated Finite Element Pavement Model}

Rectangular four - noded axisymmetric finite elements with linear interpolation functions are used in all upper layers and through the depth specified by the user for the last layer (the roadbed).

A lateral boundary is placed at a radial distance of $10 a$ from the center of the loaded area, where $a=$ radius of the loaded area. A default mesh is initially generated, but this may be modified by the user. The default mesh has the following characteristics:

In the radial direction, the total width of 10 radii is divided into four regions. Within any region, all elements have the same horizontal dimension. The first region, between 0 and 1 radius, is equally divided into four elements; the second region, between 1 radius and 3 radii, is equally divided into four elements; the third region, between 3 radii and 6 radii, is equally divided into three elements; and the fourth region, between 6 radii and 10 radii, is equally divided into two elements.

Within any layer, all elements have the same vertical dimension. The number of elements in each layer in the vertical direction is dependent on the layer thickness, but at least four elements are used in the top (AC) layer, and at least two elements are used in all other layers. A typical default finite element mesh is shown in Fig. 1.

Displacements, stresses and strains are computed only within the region modeled by finite elements. The non-linear analysis consists of several iterations. A linear analysis is performed in each iteration, after which the resilient modulus of each finite element is revised if necessary. 


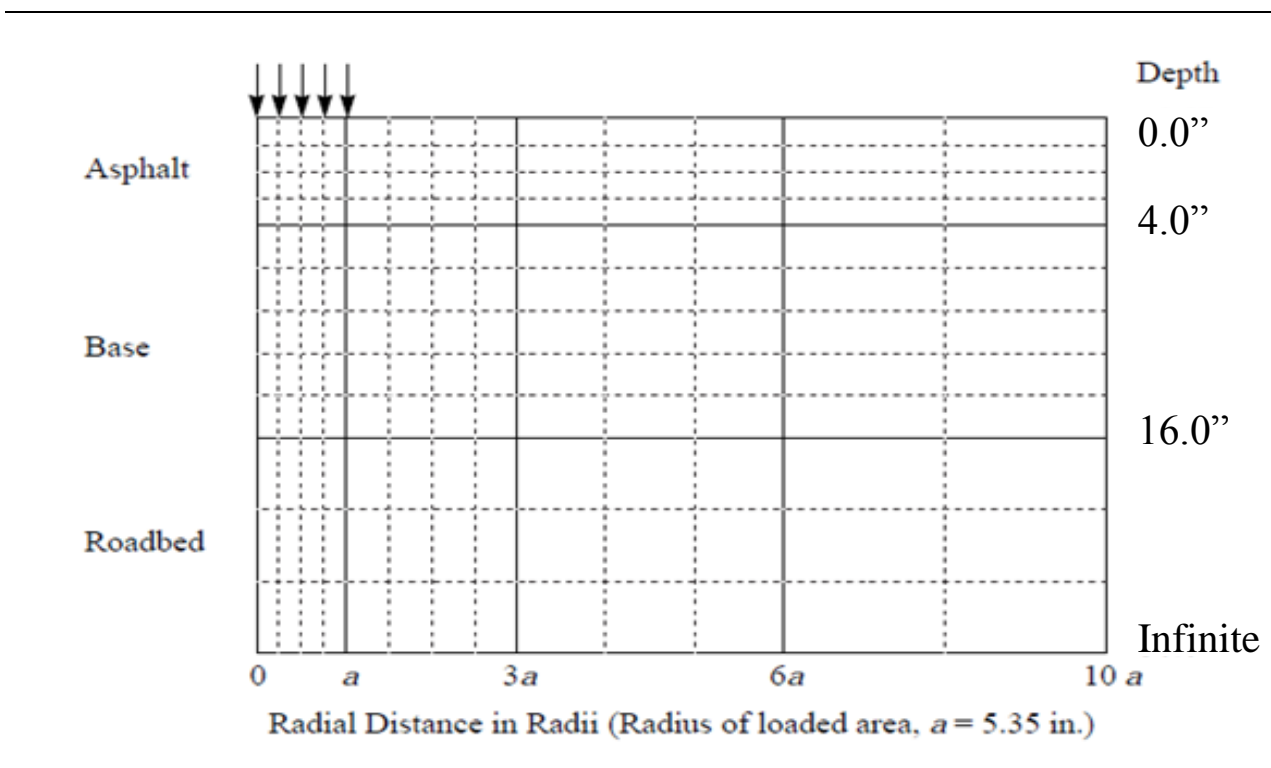

Figure 1: Typical Finite Element Mesh

\subsection{Tested Sections in the Present Reseach}

The supposed road sections are constructed on different subbase thicknesses. Bituminous surface course consists of two layers, 2.0 inches wearing course and 2.0 inches binder course. Base course constructed from 12.0 inchescompacted crushed dolomite. The thickness of sand subbase was variable and its height differs from 0.0 to 12.0 inches. Table 1 shows the thickness of different layers, resilient modules, angle of internal friction, cohesion and poison's ratio. The cohesion (C) and angle of internal friction $(\varphi)$ of different subgrade types is taken from field data (boring) in various sites in Alexandria. Axle load is constant equal $9000 \mathrm{Ib}$, Tire pressure is taken as $100 \mathrm{psi}$, air voids of asphalt layer assumed 4.0 vol$\%$ and pavement temperature supposed as $104{ }^{\circ} \mathrm{F}$.

Table 1: Properties of pavement layers

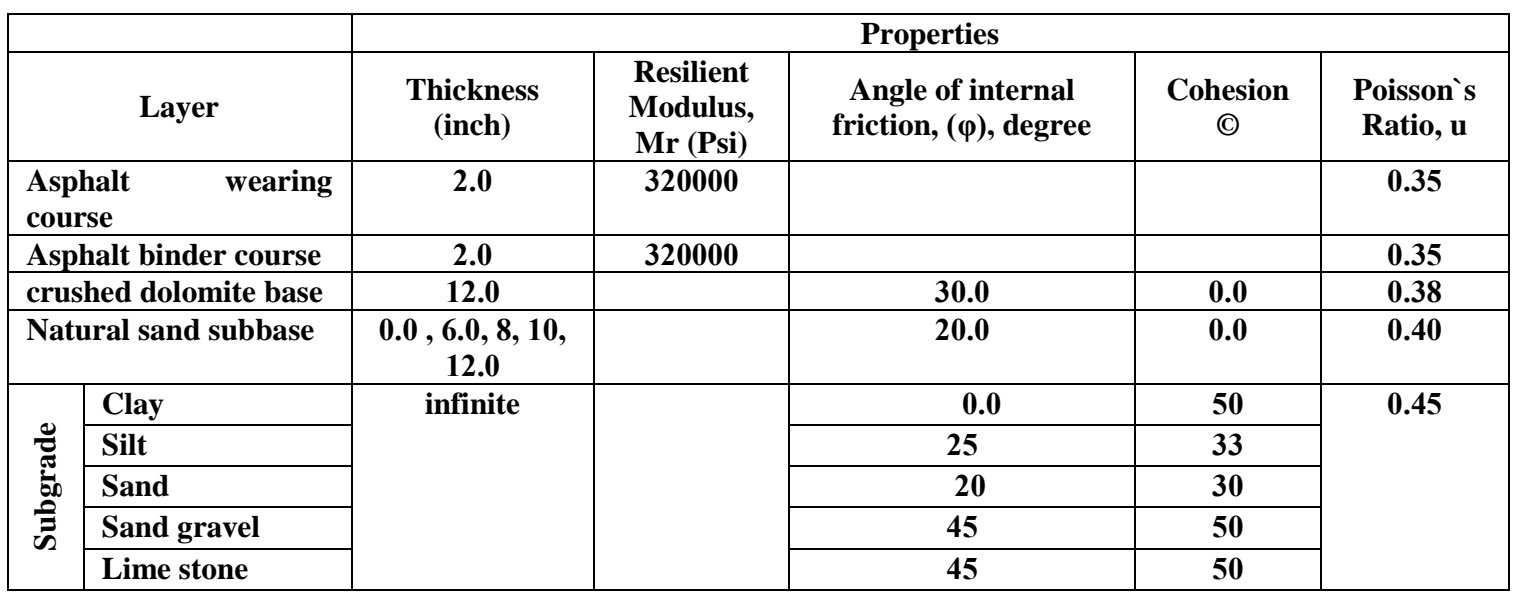




\section{Results and Discussion}

The results show that with respect to the effect of subbase thickness on different outputs, it can be seen from table 2 that using a reasonable subbaselayer (6 inches) reduces the compressive strain in asphalt layer and on the top of subgrade. But increasing the depth of subbase layer increases that strain and consequently increasing Total expected rut depth of pavement. When looking at the maximum tensile strain, it can be seen that it increases with the increase of subbas thickness. This is compatible with previous studies [16, 17]. Gillespie et al stated that changes in the subbase thickness have modest effect on flexible pavement fatigue damage.

Table 2: Effect of Subbase Thickness on Pavement responses

\begin{tabular}{|l|c|c|c|c|c|}
\hline Subbase Thickness & $\mathrm{H}=0$ & $\mathrm{H}=6$ in & $\mathrm{H}=8$ in. & $\mathrm{H}=10$ in. & $\mathrm{H}=12$ in. \\
\hline $\begin{array}{l}\text { Max. Tensile Strain in } \\
\text { Asphalt Layer }\end{array}$ & $2.26 \mathrm{E}-05$ & $2.53 \mathrm{E}-05$ & $2.60 \mathrm{E}-05$ & $2.66 \mathrm{E}-05$ & $2.67 \mathrm{E}-05$ \\
\hline $\begin{array}{l}\text { Average Compressive Strain } \\
\text { in asphalt layer }\end{array}$ & $7.24 \mathrm{E}-06$ & $4.16 \mathrm{E}-06$ & $6.04 \mathrm{E}-06$ & $7.74 \mathrm{E}-06$ & $8.68 \mathrm{E}-06$ \\
\hline $\begin{array}{l}\text { Max comp. strain at top of } \\
\text { subgrade }\end{array}$ & $7.85 \mathrm{E}-04$ & $4.69 \mathrm{E}-4$ & $4.20 \mathrm{E}-04$ & $3.69 \mathrm{E}-04$ & $3.27 \mathrm{E}-04$ \\
\hline $\begin{array}{l}\text { Fatigue life of asphalt } \\
\text { pavement (ESAL) }\end{array}$ & $6.44 \mathrm{E}+05$ & $3.77 \mathrm{E}+5$ & $5.80 \mathrm{E}+05$ & $7.84 \mathrm{E}+05$ & $9.21 \mathrm{E}+05$ \\
\hline $\begin{array}{l}\text { Total expected rut depth of } \\
\text { pavement. (in) }\end{array}$ & $4.82 \mathrm{E}-01$ & $4.59 \mathrm{E}-01$ & $4.76 \mathrm{E}-01$ & $4.90 \mathrm{E}-01$ & $4.97 \mathrm{E}-01$ \\
\hline $\begin{array}{l}\text { Expected rut depth in the } \\
\text { asphalt course. (in) }\end{array}$ & $5.16 \mathrm{E}-02$ & $4.47 \mathrm{E}-02$ & $4.95 \mathrm{E}-02$ & $5.30 \mathrm{E}-02$ & $5.48 \mathrm{E}-02$ \\
\hline $\begin{array}{l}\text { Expected rut depth in base } \\
\text { and/or subbase. (in) }\end{array}$ & $1.39 \mathrm{E}-01$ & $1.33 \mathrm{E}-01$ & $1.35 \mathrm{E}-01$ & $1.37 \mathrm{E}-01$ & $1.38 \mathrm{E}-01$ \\
\hline $\begin{array}{l}\text { Expected rut depth in the } \\
\text { roadbed soil. (in) }\end{array}$ & $2.91 \mathrm{E}-01$ & $2.82 \mathrm{E}-01$ & $2.92 \mathrm{E}-01$ & $2.99 \mathrm{E}-01$ & $3.04 \mathrm{E}-01$ \\
\hline
\end{tabular}

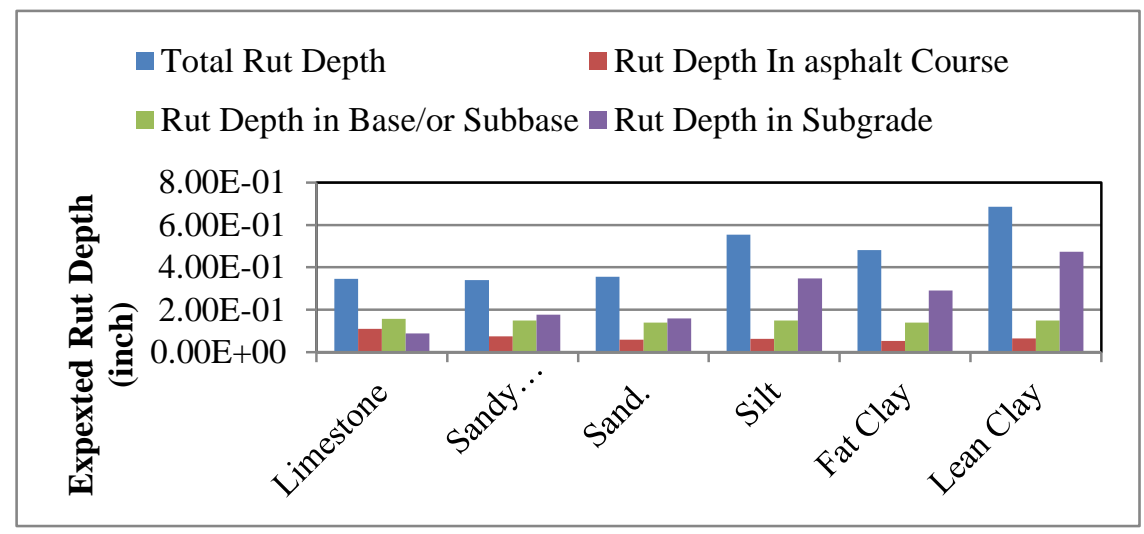

Figure 2: The Effect of Subgrade type on Flexible Pavement Rutting Depth 


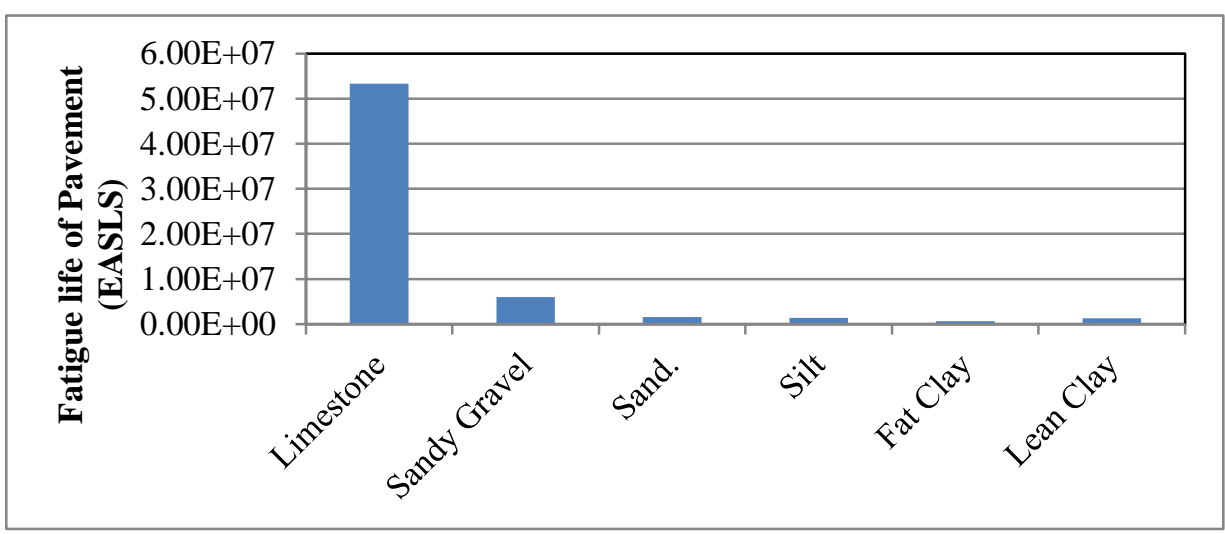

Figure 3: Relationship Between Pavement Type and Fatigue Life of Pavement

Another investigated parameter which influences pavement response is the subgrade type. As can be instantly seen from figures 2 and 3 . The limestone subgrade which has the greatest modulus exhibited lower total expected rut depth of pavement and longer fatigue life of asphalt pavement (ESALs), while weak soils like silt, fat clay and lean clay exhibited higher total expected rut depth of pavement and shorter fatigue life of asphalt pavement (ESALs). And this is due to the decrease of compressive strain in the subgrade layer with increasing stiffness [18]. It can also be seen from figure 2, that for strong roadbed soil like lime stone, the total rut depth expected in pavement was mainly consisted of rut depth in asphalt course and base/ or subbase (red and green respectively), while rut depth in subgrade (purple) was the minor value of total rut depth (blue). For very weak soils like silt, fat clay and lean clay, rutting mainly happened in subgrade while other layers rut depth was minor.

\section{Conclusions}

From the last section, the following conclusions are derived:

1. Using a reasonable subbase layer reduces the rut depth of pavement while the increase in subbase thickness cause increase in rutting. The ideal value of subbase thickness is 6.0 in. according to the assumptions of this study.

2. Tensile strain in asphalt layer increases with the increase of subbbase thickness.

3. Total expected rut depth of pavement as well as expected rut depth in the asphalt course increase with the decrease of subgrade stiffness.

4. Fatigue life of pavement increases with the increase of subgrade stiffness.

\section{References}

[1] Barksdale RD, Itani SY(1989). Influence of aggregate shape on base behavior, transportation research record 1227, Transportation Research Board, National Research Council, Washington, D.C.

[2] Zakaria M, Leest G (1996). Rutting characteristics of unbond aggregate layers, Constr.Build.Mater.10(3).

[3] Giroud JP, Han J (2004). Design method for geogrid - reinforced unpaved roads. I. Development of design method, II. Calibration and Applications. J. Geotechnical Geoenvironmental Eng. Am. Soc. Civil Eng. Vol.130, AsCE.

[4] Xu T, Huang X (2011).Investigation into causes of in-place rutting in 
asphalt pavement. J. Constr. Build. Mater. P.28.

[5] Mulungye RM et. al. (2007). Finite element modeling of flexible pavements on soft soil subgrades, J. Mater. Design 28.

[6] Cardone F, Cerni G, Virgili A, Camilli S (2011). Characterization of permanent deformation behavior of unbond granular materials under repeated triaxialloading. J. Constr. Build. Mater. P.28.

[7] Yoder, E. J., and Witczak, M. W., "Principals of Pavement Design, 2nd ed., Wiley, New York, 1975.

[8] El-Hamrawy, S., "Effect of Wheel Load, Tire Pressure and Subgrade Stiffness on Flexible Pavements Responses)", Al-Azhar Engineering $6^{\text {th }}$ International Conference, Sept. 2000, PP. 489-502.

[9] Fernando, E. G., Musani, D., Park, D., and Liu, W., "Evaluation of Effects of Tire Size and Inflation Pressure on Tire Contact Stresses and Pavement Response", Texas Transportation Institute; Texas Department of Transportation; Federal Highway Administration, 2006.

[10] Sharaf, E. A., "Effect of Increased Axle Load on Pavement Maintenance and Vehicle Operating Costs: A Case study in Egypt", Arab Roads Journal, Cairo, 2nd Edition, 2000, PP. 10-24.

[11] Raad, L. and Figueroa, J. L. (1980). "Load Response of Transportation Support Systems." Journal of Transportation Engineering, ASCE, Vol. 16, No.TE1, pp.111-128.

[12] Harichandran, R.S., Baladi, G. Y., and Yeh, M-S. (1989). "Development of a computer program for design of pavement systems consisting of layers of bound and unbound materials," Report No. FHWA-MI-
RD-89-02, Michigan Department of Transportation, Lansing, Michigan.

[13] Brunton, J. M., and De Almeida, J. R. (1992). "Modeling Material Nonlinearity in a Pavement Backcalculation Procedure." Transportation Research Record 1377,TRB, National Research Council, Washington, D.C., pp. 99106.

[14] Park, S., and Lytton, R. L. (2004). "Effect of Stress-Dependent Modulus and Poisson's Ratio on Structural Responses in Thin Asphalt Pavements." Journal of Transportation Engineering, Vol. 130, No. 3, pp. 387-394.

[15] Michpave Manual Workbook. pp 5$36,5-37$

[16] Hothan,j. "ZumEinfluss der Zugspannungsaufnahmenfähigkeit in ungebundenen Tragschichten auf die Anstrengung Von Asphaltbefestigungen- Eine Modelluntersuchung" - Dissertation, Universität Honnover 1986.

[17] T.D. Gillespie, S. M. Karamihas, M. W. Sayers, M. A. Nasim, N. Ehsan, D. Sebon (1993) "Effect of Heavy Vehicle Characterstics on Pavement Response and Performance" NCHRP Report 353, pp. 45-46

[18] Barry R. Christopher, Ph.D., P.E., Charles Schwartz, Ph.D., P.E. and Richard Boudreau, P.E. May 2006, publication No. FHWA NHI-05-037, Federal Highway Administration NHI Course No. 132040, "Geotechnical Aspects of Pavements" Reference Manual / Participant 